\title{
Detailed Transient Multiphysics Model for Fast and Accurate Design, Simulation and Optimization of a Thermoelectric Generator (TEG) or Thermal Energy Harvesting Device
}

\begin{abstract}
ALFRED PIGGOTT $\mathbb{D}^{1,2}$
1.-Applied Thermoelectric Solutions LLC, Novi, MI 48376, USA. 2.-e-mail: Alfred@ThermoelectricSolutions.com

Described herein is a detailed and comprehensive multiphysics model of a thermoelectric generator (TEG). The one-dimensional model uses electricalthermal analogies solved for transient response using SPICE. There are many advantages and applications of thermoelectric generators. Wider use and application advancements are generally limited by the tools available for engineering and scientific studies. Currently, available modeling tools are limited by some combination of speed, platform capabilities, or missing physics that are not used or assumed to be negligible. The TEG module model herein is made up of two sub-models, the thermoelement model and the non-thermoelement model. Rather than a lumped thermoelement model, the model herein makes use of distributed physics that include the following: Thomson effect, temperature dependence, mass, Joule heat, thermal resistance, Seebeck effect, and electrical resistance. The non-thermoelement model takes into account temperature dependence and simulates Joule heat generation, thermal resistances, thermal and electrical interface resistances, and mass for and between the ceramic, copper, and solder. The comprehensive model herein was correlated to experimental data that simultaneously varied electrical current and hot and cold side temperatures with time. Very minimal adjustments to reported thermoelectric properties were required to almost perfectly match the experimental transient power output. The effects of the non-thermoelement model, distributed Thomson effect model and distributed temperature dependent property model were quantified. The model ran very quickly, taking 2.5 real-time seconds to run a $4000 \mathrm{~s}$ transient simulation.
\end{abstract}

Key words: Thermoelectric, thermoelectric generator, TEG, thermal energy harvesting, SPICE, Thomson effect, Seebeck effect, Peltier effect, module, transient, device

\section{INTRODUCTION}

Thermoelectric generators (TEG) are solid-state devices that utilize the Seebeck effect to convert a temperature difference and heat flux directly into electricity.
As an energy conversion technology, thermoelectric generators have many advantages. ${ }^{1}$ Thermoelectric generators have no moving parts, and this makes them very reliable. Thermoelectric generators are completely silent, scalable from microwatts to kilowatts and beyond, require no greenhouse gases to operate, are mountable in any orientation, can operate in zero and high-g conditions, are very compact, and have no limits on fuel types that can be used to generate the required heat. 
Common heat sources include ${ }^{1}$ radioactive decay, waste heat, body heat, renewable sources, and combustion. An example of a radioactive decay source is plutonium-238. Waste heat sources include automotive exhaust, steel foundries, wood stoves, gas flares, candles, hot water pipes, solar photovoltaic panels, and electronics. Renewable sources include geothermal and solar thermal sources. Combustion heat can be utilized from either external or internal combustion.

Applications can be categorized into five main groups. ${ }^{2}$ These are extreme environment, waste heat recovery, microgeneration for sensors and electronics, combined heat and power (CHP), and solar thermal. Examples of extreme environment applications include spacecraft, Mars rovers, lunar power stations, power generation in Antarctica, flashing light buoys, lighthouses, and nuclear pacemakers. Other extreme environment applications that do not utilize radiological sources include thermoelectric generators for well heads, offshore platforms, pipelines (oil, gas, water), telecommunication sites, and navigational aids. Microgeneration for sensors and electronics applications include wireless sensor networks (WSN), environmental monitoring, low-power Internet of Things (IoT) applications, body-heat powered wrist watches, body-heat powered flashlights, and body-heat powered medical devices. ${ }^{3}$ Examples of combined heat and power (CHP) include biomass cooking stoves, camping stoves and grills.

Despite the many applications, the wider adoption of thermoelectric generators and the refinement of current applications is limited. One of the limiting factors is the tools available for engineering and research of thermoelectric generator applications. Thermoelectric generator modeling and simulation is one such tool.

Often for modeling and simulation, simplified and ideal equations are used; however, these equations do not capture all of the physics and result in significantly lower accuracy and a longer application development and research cycles. Other tools, such as three-dimensional modeling, can be more accurate, but they run slower, the cost is high, and important physics are often assumed negligible.

Improving the speed of the model can reduce lead time and costs. Conversely, with a faster model, the cost and lead time can be held constant, and the scope of the investigation expanded. Modeling accuracy is another very important feature. An accurate model again means fewer expensive and timeconsuming prototypes, tests, and experiments needed for final design or discovery validation and less time required to find good model correlation to experiment or test data.

Currently, within the literature, there are many exceptional TEG models. However, it is difficult to find a model with the optimal or comprehensive set of desirable detailed physics for maximum accuracy as well as desired model platform capabilities and speed.

To differentiate from the current work in the literature, the first objective of the work herein is to explore the development of a thermoelectric generator model that includes a comprehensive set of desirable physics for very accurate simulation and at the same time runs very fast. The second objective is to validate the output of this developed comprehensive model against challenging experimental data that simultaneously applies a transient electrical current and transient hot and cold side temperatures. The third objective is to understand the model output sensitivity to each of the modeling features that were added.

The comprehensive model herein was developed and validated against the experimental data. The model required minimal correlation to almost exactly match the experimental data. The added model features were grouped into three main areas to study their sensitivity. These areas are the distributed Thomson effect model, the temperature dependent distributed thermoelectric property model, and the temperature dependent non-thermoelement model. This temperature dependent non-thermoelement model is defined as every part of the thermoelectric module with exception of the $\mathrm{Bi}_{2} \mathrm{Te}_{3}$ thermoelements. It was found that the distributed temperature dependent thermoelectric property model and the non-thermoelement portions of the model greatly impact the accuracy of the comprehensive model. Modeling the distributed Thomson effect had a very small impact on the accuracy of the comprehensive model.

\section{Literature Survey}

The literature contains three prominent types of modeling platforms for thermoelectrics. The first of these three types is the three-dimensional model. These models use finite element or finite volume methods. They have been developed in ANSYS ${ }^{\text {TM4 }}, 5$ $\mathrm{Cosmol}^{\mathrm{TM} 6}$ and Fluent ${ }^{\mathrm{TM} 7}$ (now ANSYS ${ }^{\mathrm{TM}}$ ). The second type are models that have been created in programming platforms such as Matlab ${ }^{\text {TM8,9 }}$ and the third type uses electrical-thermal analogies solved in Simulation Program with Integrated Circuit Emphasis (SPICE). ${ }^{10-18}$

SPICE modeling ${ }^{19,20}$ is known to be fast. An identical thermoelectric device was modeled in both SPICE and Fluent ${ }^{\mathrm{TM}}$. The SPICE model was up to $430 \%{ }^{7}$ faster with results of both models being in good agreement. SPICE has been used to model thermoelectric cooling, showing very good agreement with experimental data. ${ }^{10}$ Three-dimensional models are exceptional for understanding heat flows and temperature fields in irregular geometries which makes them good for understanding spreading and constriction thermal resistance. For thermoelectric modules such as the one modeled herein in Fig. 1, geometries are typically rectangular and 


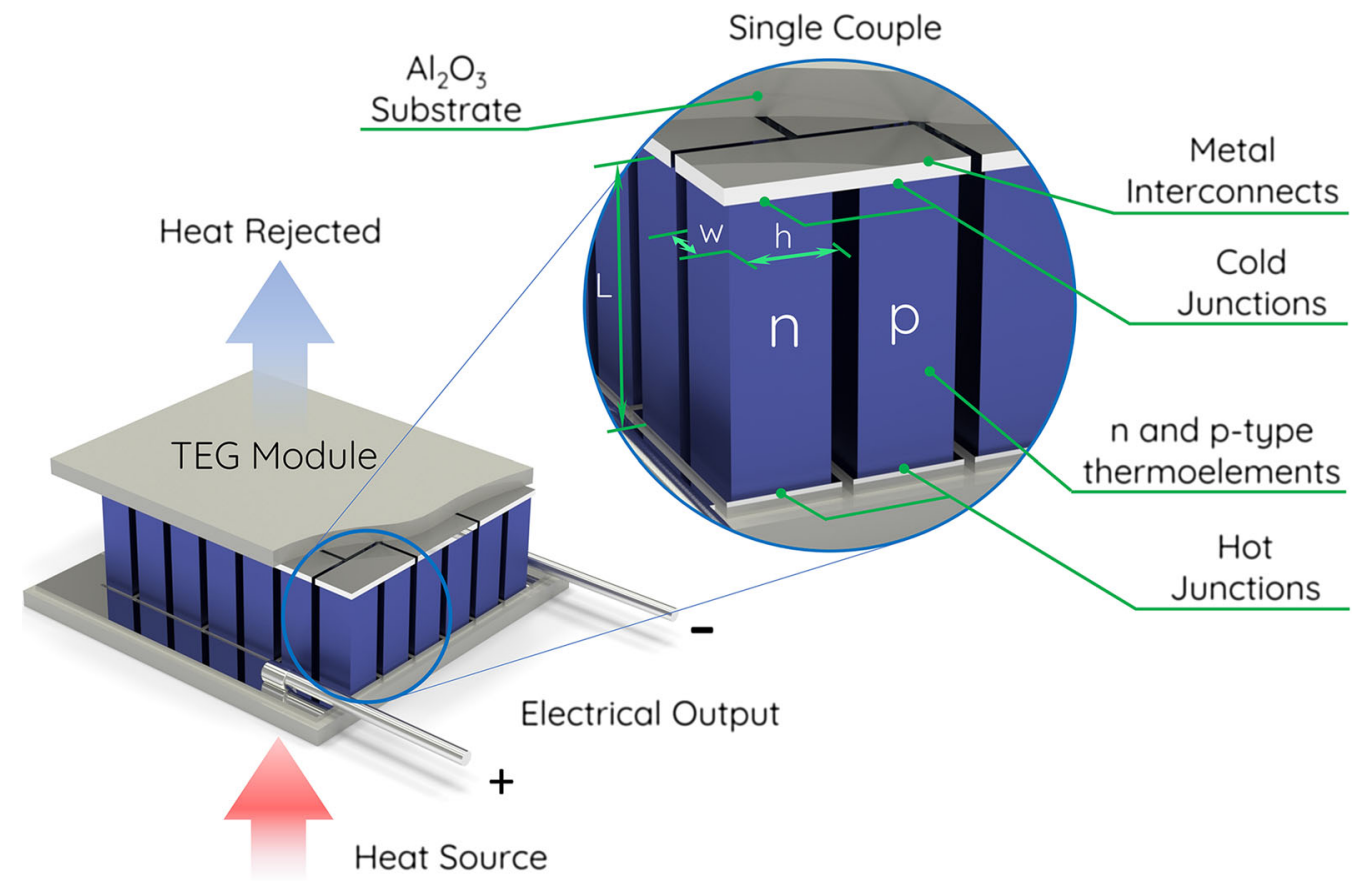

Fig. 1. Schematic of a TEG module.

hot and cold sources are distributed relatively evenly. This situation may negate some of the advantages of three-dimensional models.

Compared with other modeling methods, threedimensional models can be slower running due to many calculations within the mesh. If the effects of changing geometry are studied in a three-dimensional model, more time may also be required to change CAD models and to re-mesh them, depending on the software package. Models built in programming platforms are fast and have many features that make them almost infinitely flexible. The disadvantage is these programming platform models can be difficult and time consuming to build and change. Additionally, time is needed to configure ODE solvers which may not always work properly. An advantage of SPICE models is that these solvers are handled in the background and automatically optimized for the task. Additional advantages of SPICE models include the ability to simultaneously model and develop thermoelectric controls such as Proportional Integral Derivative $(\mathrm{PID})^{21}$ and Maximum Power Point Tracking (MPPT) controllers. ${ }^{22}$ Considering the many advantages of the SPICE modeling platform, it was chosen for the work herein.

To make certain the accuracy of the model herein was maximized, a list of desired physics features was created before the model development began. This list includes distributed mass transient modeling capability, distributed temperature dependent thermoelement material properties, temperature dependent non-thermoelement properties, all thermoelectric effects including (Thomson, Seebeck and
Peltier), thermal interface resistances, electrical interface resistances, thermal resistances, distributed thermoelement heat flows (Joule, Fourier and Thomson), and heat generation within the solder and metal interconnects between the thermoelements and within the electrical interface resistances.

The literature shows that many, but not all items in this list of desired physics have been previously used for thermoelectric generator modeling, but not in a complete combination. For example, the Thomson effect has been used in SPICE models, but the model was steady-state model, ${ }^{23}$ not transient and not distributed. Conversely, other models are setup for transient modeling, however, they do not contain the Thomson effect. ${ }^{14}$ Sometimes temperature dependent thermoelement properties are used with transient models but the models are lumped thermoelement mass ${ }^{9,15,24}$ not distributed mass or heat flows. Even the most detailed and comprehensive models ${ }^{5}$ do not contain details such as temperature dependent non-thermoelement properties and complete electrical and thermal interface resistances.

\section{Background}

\section{Ideal, Simplified Equations}

Zero-dimensional ideal and simplified equations ${ }^{25}$ have been developed (Eqs. 1-4), for calculating thermoelectric generator power output. Although missing many of the desirable physics for accurate calculations, these equations work well for understanding the heat flows through and power generated by a thermoelectric couple. 
Here $Q_{\mathrm{h}}$ is the heat input to the thermoelectric generator couple. $P$ is the power output and $Q_{\mathrm{c}}$ is the heat leaving the couple. $\alpha_{\mathrm{h}}$ is the Seebeck coefficient at $T_{h}$ and $\alpha_{c}$ is the Seebeck coefficient at $T_{\mathrm{c}} . K$ is the thermal conductance of the couple. $I$ is the electrical current through the couple and $\tau$ is the Thomson coefficient. $R$ is the electrical resistance of the couple.

$$
\begin{gathered}
\dot{Q}_{\mathrm{h}}=\alpha_{\mathrm{h}} T_{\mathrm{h}} I+K\left(T_{\mathrm{h}}-T_{\mathrm{c}}\right)-\frac{I^{2} R}{2}-\frac{\tau I\left(T_{\mathrm{h}}-T \mathrm{c}\right)}{2} \\
\dot{Q}_{\mathrm{c}}=\alpha_{\mathrm{c}} T_{\mathrm{c}} I+K\left(T_{\mathrm{h}}-T_{\mathrm{c}}\right)+\frac{I^{2} R}{2}+\frac{\tau I\left(T_{\mathrm{h}}-T \mathrm{c}\right)}{2}
\end{gathered}
$$

Equations 3 and 4 show subtracting $\dot{Q}_{\mathrm{c}}$ from $\dot{Q}_{\mathrm{h}}$ provides the electrical power output of the couple.

$$
P=\dot{Q}_{\mathrm{h}}-\dot{Q}_{\mathrm{c}}
$$

By substitution,

$$
P=\left(\alpha_{\mathrm{h}} T_{\mathrm{h}}-\alpha_{\mathrm{c}} T_{\mathrm{c}}\right) I-I^{2} R-\tau I\left(T_{\mathrm{h}}-T_{\mathrm{c}}\right)
$$

\section{The Thomson Effect}

When an electric current travels through a temperature gradient in a conductor, heat is either absorbed or released in the conductor. This is known as the Thomson effect. ${ }^{26}$ The effect is continuous along the length of current flow and is a separate phenomenon from Joule heat.

The Thomson coefficient ${ }^{27}$ is described by Eq. 5 .

$$
\tau=T \frac{\mathrm{d} \alpha}{\mathrm{d} T}
$$

Here $\alpha$ is the temperature dependent Seebeck coefficient and $T$ is temperature of the material. Materials with a positive Thomson coefficient absorb heat when electrical current travels from hot to cold and reject heat when electrical current travels from cold to hot. Materials with a negative Thomson coefficient show the opposite behavior. ${ }^{28}$ The materials used for the study herein $\left(\mathrm{Bi}_{2} \mathrm{Te}_{3}\right)$ can change from positive to zero to negative Thomson coefficient as temperature increases.

$$
\dot{Q}_{\text {th }}=n \tau I \Delta T
$$

Equation 6 describes ${ }^{23}$ the rate of heat either absorbed or rejected along $n$ conductors connected electrically in series and subjected to $\Delta T=T_{\mathrm{h}}-T_{\mathrm{c}}$ when current $I$ flows from $T_{\mathrm{h}}$ to $T_{\mathrm{c}}$ or vice versa.

\section{MATERIALS AND METHODS}

The thermoelectric module model is divided into two main parts, which are described separately herein. The first part in Fig. 2, models only the thermoelements and is where thermoelectric physics are simulated. The second part of the model, in Fig. 3, is referred to as the temperature dependent non-thermoelement model. This temperature dependent non-thermoelement model is where every part of the TEG module, except for the thermoelements are simulated. For example, in the temperature dependent non-thermoelement model, electrical and thermal contact resistances, mass, and thermal and electrical resistances are simulated for copper interconnects, $\mathrm{Al}_{2} \mathrm{O}_{3}$ plates and solder. Additionally, thermal boundary conditions at the $\mathrm{Al}_{2} \mathrm{O}_{3}$ surface are specified here.

\section{Thermoelement Model Description}

Figure 2 describes the electrical-thermal analogy model of the thermoelements of the TEG module. The model has been adapted from Ref. 13. This model combines both the $p$-type and $n$-type thermoelements of the module into one large thermoelement of length $L$ described in Fig. 1 and Table I. The total cross-sectional area of the combined single thermoelement is $A_{\mathrm{T}}=2 n A$ where $A=h w, n$ is the number of couples in the TEG module and $A$ is the cross sectional area for which heat and electrical current flow normal to in a single thermoelement. Additionally, this one-dimensional model divides the thermoelement up into discrete elements along the length of current and heat flow, 50 in total. These elements are shown in Fig. 2. This discretization models distributed heat flows and mass. This makes the transient one-dimensional model possible.

This model was originally used for thermoelectric cooling and has been adapted herein for thermoelectric power generation. The adaptations include the addition of the distributed Thomson effect, directional changes in Peltier cooling and heating, electrical current flow direction, Seebeck driven electrical current rather than source driven current and distributed temperature dependent properties at each of 50 finite elements that make up the length of the thermoelement. Additionally, the thermoelement model has been combined with a temperature dependent non-thermoelement model of Fig. 3, to make a more complete model. The nonthermoelement portion of the model herein will be described in "Temperature Dependent Non-thermoelement Model Description" section.

The material properties of the thermoelement are calculated at each of the fifty finite elements. The average temperature across each finite element is used for the calculation.

\section{Temperature Dependent Non-thermoelement Model Description}

The temperature dependent non-thermoelement model can be seen in the schematic of Fig. 3. This model consists of every feature of the thermoelectric TEG module except for the thermoelements. The model has both thermal and electrical portions. On the thermal side, the features include the $\mathrm{Al}_{2} \mathrm{O}_{3}$ 


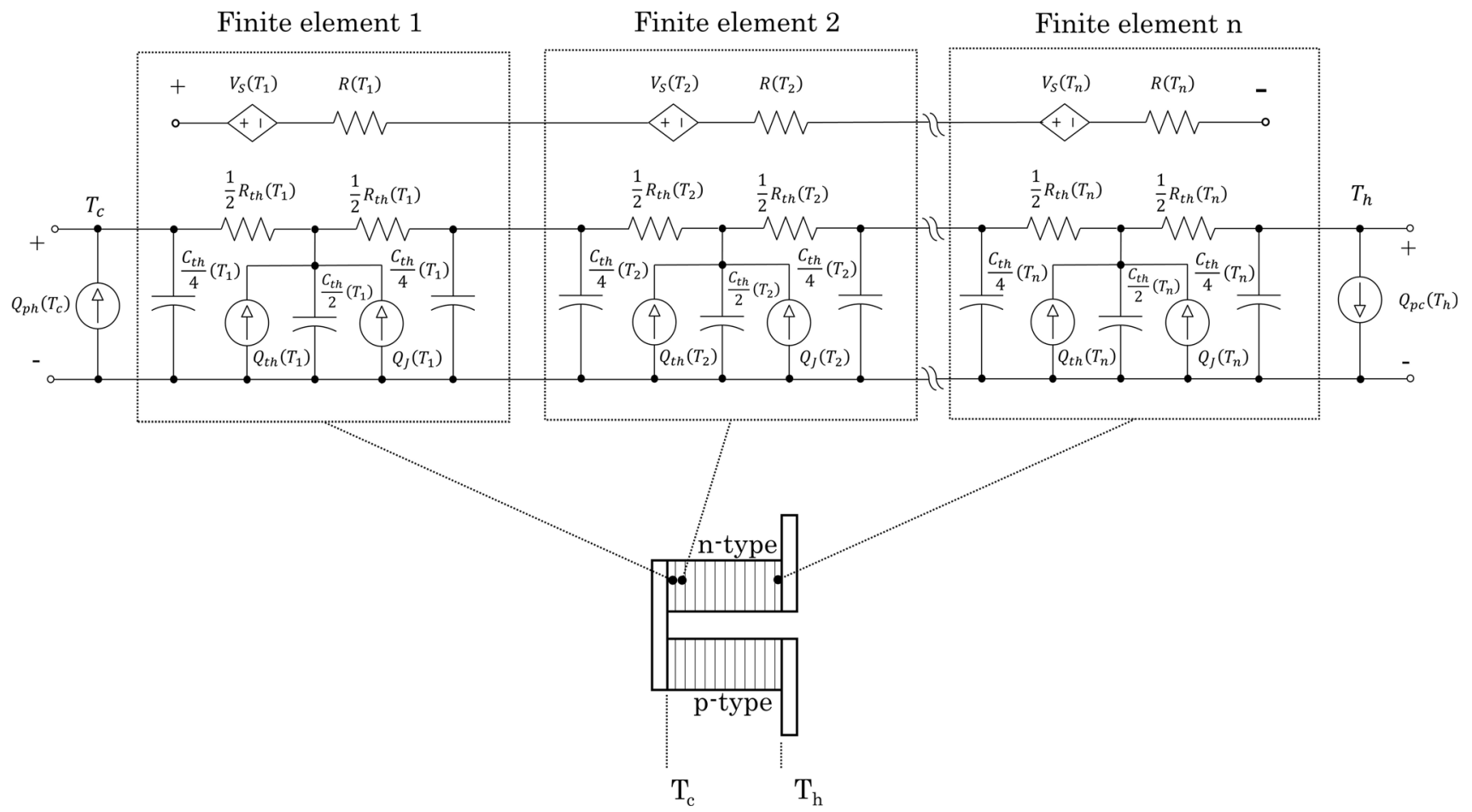

Fig. 2. Electrical and thermal model of the thermoelements. Modified from Ref. 13. Distributed Thomson effect added, temperature dependence added.
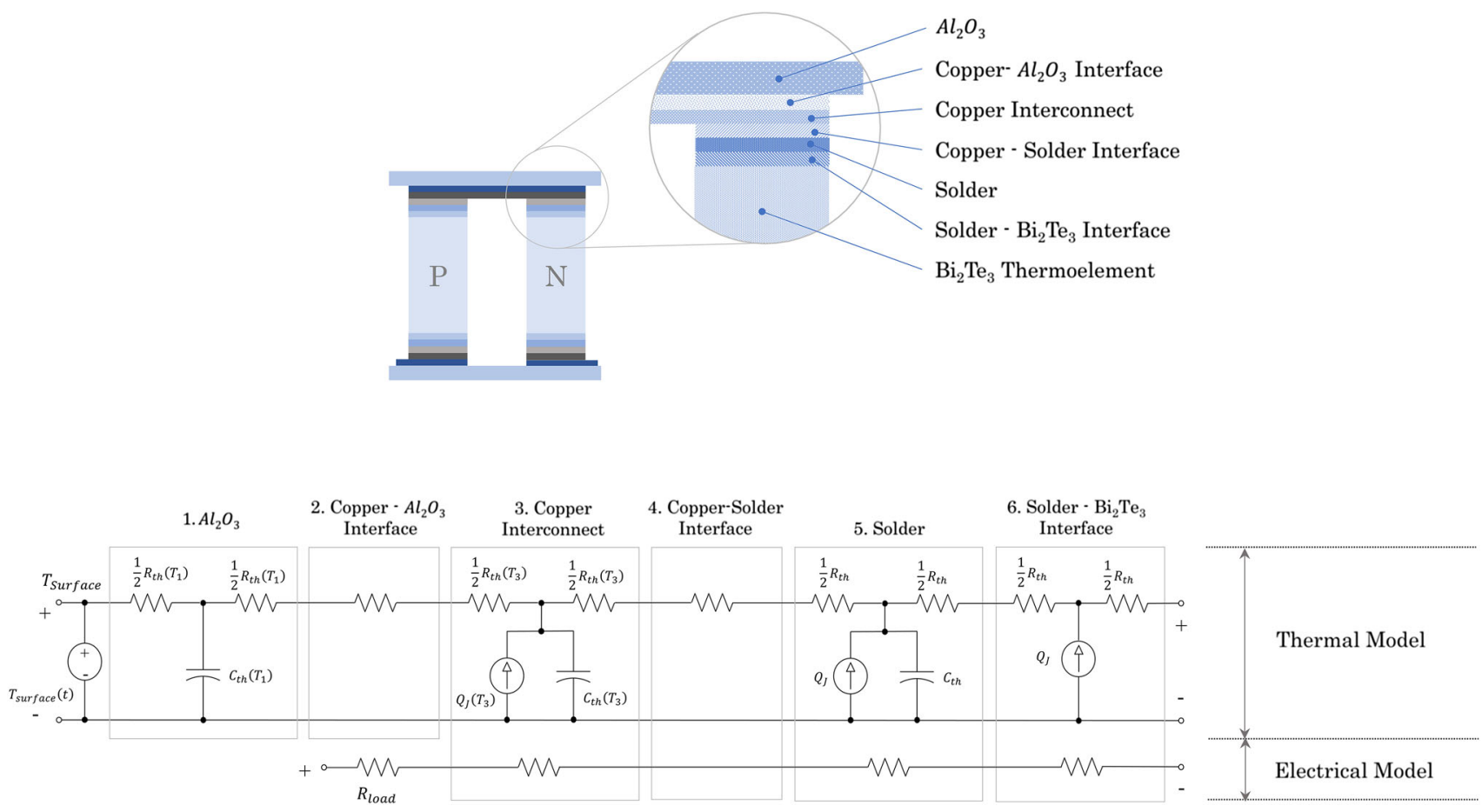

Fig. 3. Non-thermoelement SPICE model.

plate thermal resistance, the thermal interface between the $\mathrm{Al}_{2} \mathrm{O}_{3}$ and the copper interconnects, the thermal resistance of the copper interconnects, the thermal interface between the copper interconnects and solder joints, the solder thermal resistance, and the thermal interface between the $\mathrm{Bi}_{2} \mathrm{Te}_{3}$ and the solder. The electrical model features consist of electrical interface resistance between the $\mathrm{Bi}_{2} \mathrm{Te}_{3}$ and the solder, the electrical resistance of the solder, the electrical resistance of the copper 


\section{Table I. Thermoelement properties}

\begin{tabular}{|c|c|c|c|}
\hline Parameter & Value & Unit & Source \\
\hline Thermal conductivity, $k$ & Equation 7 & $\mathrm{~W} \mathrm{~m}^{-1} \mathrm{~K}^{-1}$ & Ref. $29^{a}$ \\
\hline Seebeck coefficient, $\alpha$ & Equation 8 & $\mathrm{VK}^{-1}$ & Ref. $29^{\mathrm{a}}$ \\
\hline Thermal resistivity, $\rho$ & Equation 9 & $\Omega \mathrm{m}$ & Ref. $29^{a}$ \\
\hline Thomson coefficent, $\tau$ & Equation 10 & $\mathrm{VK}^{-1}$ & Calculated herein \\
\hline Length, $L$ & 1 & $\mathrm{~mm}$ & Ref. $30^{\mathrm{b}}$ \\
\hline Width, $W$ & 1.4 & $\mathrm{~mm}$ & Ref. $30^{\mathrm{b}}$ \\
\hline Height, $H$ & 1.4 & $\mathrm{~mm}$ & Ref. $30^{\mathrm{b}}$ \\
\hline Number of couples, $n$ & 127 & \# & Ref. 30 \\
\hline Density, $\rho$ & 7800 & $\mathrm{kgm}^{-3}$ & Ref. 31 \\
\hline Heat capacity, $C_{p}$ & See Eq. 11 & $\mathrm{~J} \mathrm{~kg}^{-1} \mathrm{~K}^{-1}$ & Refs. $31-33^{\mathrm{c}}$ \\
\hline
\end{tabular}

${ }^{\mathrm{a}}$ From Ref. 29 , modified herein for use and correlation. ${ }^{b}$ Email confirmation from European Thermodynamics Limited. ${ }^{\mathrm{c}}$ From Refs. $31-33$, aggregated herein.

Table II. Non-thermoelement properties

\begin{tabular}{|c|c|c|c|}
\hline Parameter & Value & Unit & Source \\
\hline Thermal conductivity, $\mathrm{Al}_{2} \mathrm{O}_{3} 96 \%$ & Equation 12 & $\mathrm{~W} \mathrm{~m}^{-2} \mathrm{~K}^{-1}$ & Ref. 34 \\
\hline Specific heat capacity, $\mathrm{Al}_{2} \mathrm{O}_{3} 96 \%$ & Equation 12 & $\mathrm{~J} \mathrm{~kg}^{-1} \mathrm{~K}^{-1}$ & Refs. 34 and 35 \\
\hline Thickness, $\mathrm{Al}_{2} \mathrm{O}_{3} 96 \%$ & 0.6 & $\mathrm{~mm}$ & No citation \\
\hline Thermal conductivity, $\mathrm{Sn} / \mathrm{Pb}$ Solder & 48 & $\mathrm{~W} \mathrm{\textrm {m } ^ { - 2 }} \mathrm{K}^{-1}$ & Ref. 36 \\
\hline Thickness, Solder & 0.058 & $\mathrm{~mm}$ & No citation \\
\hline Electrical resistivity, Solder, $\rho$ & $4 \times 10^{-7}$ & $\Omega \mathrm{m}$ & Ref. 37 \\
\hline Specific heat, Solder, $C_{\mathrm{p}}$ & 167 & $\mathrm{~J} \mathrm{~kg}^{-1} \mathrm{~K}^{-1}$ & Ref. 38 \\
\hline Density, Solder, $\rho$ & 8400 & $\mathrm{~kg} \mathrm{~m}^{-3}$ & Ref. 38 \\
\hline Thermal interface resistance, Copper - Solder & $2 \times 10^{-6}$ & $\mathrm{~m}^{2}\left(\mathrm{KW}^{-1}\right)$ & Ref. 39 \\
\hline Electrical interface resistance, $\mathrm{Bi}_{2} \mathrm{Te}_{3}-$ Solder & $3.6 \times 10^{-9}$ & $\Omega \mathrm{m}^{2}$ & Ref. 40 \\
\hline Thermal interface resistance, $\mathrm{Bi}_{2} \mathrm{Te}_{3}$ - Solder & $10^{-7}$ & $\mathrm{~m}^{2}\left(\mathrm{KW}^{-1}\right)$ & Ref. 41 \\
\hline Thermal interface resistance, Copper- $\mathrm{Al}_{2} \mathrm{O}_{3} 96 \%$ & $2 \times 10^{-5}$ & $\mathrm{~m}^{2}\left(\mathrm{KW}^{-1}\right)$ & Ref. 41 \\
\hline Electrical resistivity, Copper, $\rho$ & Equation 12 & $\Omega \mathrm{m}$ & Ref. 42 \\
\hline Specific heat capacity, Copper $C_{\mathrm{p}}$ & Equation 12 & $\mathrm{~J} \mathrm{~kg}^{-1} \mathrm{~K}^{-1}$ & Ref. 35 \\
\hline Density, Copper, $\rho$ & 8490 & $\mathrm{~kg} \mathrm{~m}^{-3}$ & Ref. 36 \\
\hline Diameter, Wire & 1 & $\mathrm{~mm}$ & No citation \\
\hline Length, Wire & 70 & $\mathrm{~mm}$ & No citation \\
\hline Thickness, Copper & 0.55 & $\mathrm{~mm}$ & No citation \\
\hline Thermal conductivity, Copper & Equation 12 & $\mathrm{~W} \mathrm{~m}{ }^{-2} \mathrm{~K}^{-1}$ & Ref. 35 \\
\hline
\end{tabular}

interconnects and the resistive load on the TEG. The TEG matched load resistance used for the model was $2.330045 \Omega$. This was calculated at $413.15 \mathrm{~K}$ which is $T_{\text {ave }}=\left(T_{\mathrm{h}}-T_{\mathrm{c}}\right) / 2$ from manufacture data sheet. ${ }^{30}$ The thermoelectric properties provided herein were used to calculate the matched load with no correlation multipliers.

As in the thermoelement model, electrical-thermal analogies "Thermoelement Model Description" were again used for the temperature dependent non-thermoelement model. Here thermal capacitance was modeled using capacitors. The thermal interfaces were assumed to be massless, so no thermal capacitance was modeled. Electrical resistance of solder and copper interconnects were modeled using resistors. Electrical and thermal resistance between the solder and $\mathrm{Bi}_{2} \mathrm{Te}_{3}$ and between the copper interconnect and solder were calculated using properties from Table II. Anywhere there is electrical resistance in the electrical model, there is a corresponding Joule heat generation in the thermal model. This Joule heat was modeled using current sources. All thermal resistances were modeled using resistors.

Temperature dependent properties were calculated based on the average temperature at the location where that property was relevant. For example, the properties of $\mathrm{Al}_{2} \mathrm{O}_{3}$ were calculated by the average of the $\mathrm{Al}_{2} \mathrm{O}_{3}$ surface temperature and the temperature at the interface resistance between $\mathrm{Al}_{2} \mathrm{O}_{3}$ and copper.

Temperature independent material properties for the temperature dependent non-thermoelement model can be found in Table II, whereas temperature dependent properties can be calculated using a combination of Eq. 12 and the coefficients in Table III.

The properties in Table III were obtained by fitting experimental data throughout different ranges of temperature. Due to polynomial fitting, 
Table III. Copper and $\mathrm{Al}_{2} \mathrm{O}_{3}$ temperature dependent property coefficients

\begin{tabular}{|c|c|c|c|c|c|}
\hline Coefficient & $\begin{array}{c}\text { Thermal } \\
\text { conductivity, } \\
\text { Copper, } \boldsymbol{k}\end{array}$ & $\begin{array}{c}\text { Specific } \\
\text { heat capacity, } \\
\text { Copper, } C_{p}\end{array}$ & $\begin{array}{c}\text { Thermal } \\
\text { conductivity, } \\
\mathrm{Al}_{2} \mathrm{O}_{3}, k\end{array}$ & $\begin{array}{c}\text { Specific } \\
\text { heat capacity, } \\
\mathrm{Al}_{2} \mathrm{O}_{3}, C_{p}\end{array}$ & $\begin{array}{l}\text { Electrical } \\
\text { resistivity, } \\
\text { Copper, } \rho\end{array}$ \\
\hline$a$ & 0 & 0 & $8.70093 \times 10^{-14}$ & $3.41262 \times 10^{-13}$ & $1.24794 \times 10^{-17}$ \\
\hline$b$ & 0 & 0 & $-2.03101 \times 10^{-10}$ & $-8.12754 \times 10^{-10}$ & $-5.51003 \times 10^{-14}$ \\
\hline$c$ & 0 & 0 & $1.94417 \times 10^{-7}$ & $7.75161 \times 10^{-7}$ & $9.37995 \times 10^{-11}$ \\
\hline$d$ & $-3.78333 \times 10^{-6}$ & $5.04166 \times 10^{-6}$ & $-9.87683 \times 10^{-5}$ & $-3.71047 \times 10^{-4}$ & $-7.60935 \times 10^{-8}$ \\
\hline$e$ & $4.61500 \times 10^{-3}$ & $-6.31250 \times 10^{-3}$ & $2.86331 \times 10^{-2}$ & $8.73298 \times 10^{-2}$ & $3.04226 \times 10^{-5}$ \\
\hline$f$ & -1.89096 & 2.58083 & -4.72240 & -5.82914 & $1.36762 \times 10^{-3}$ \\
\hline$g$ & $6.20600 \times 10^{2}$ & 52.00000 & $4.00106 \times 10^{2}$ & $1.28614 \times 10^{2}$ & 1 \\
\hline$h$ & 1 & 1 & 1 & 1 & $1.00000 \times 10^{-8}$ \\
\hline
\end{tabular}

the accuracy outside of this fitted range cannot be guaranteed and may produce incorrect results. The thermal conductivity of copper, specific heat capacity and thermal conductivity of $\mathrm{Al}_{2} \mathrm{O}_{3}$ were all fitted from $100 \mathrm{~K}$ to $600 \mathrm{~K}$. The specific heat capacity of $\mathrm{Al}_{2} \mathrm{O}_{3}$ was fitted from $59 \mathrm{~K}$ to $632 \mathrm{~K}$ and the electrical resistivity of copper was fitted between $80 \mathrm{~K}$ and $1358 \mathrm{~K}$. The specific heat capacity of Eq. 11 was fitted between $360 \mathrm{~K}$ and $570 \mathrm{~K}$. Two different data sets were available for $\mathrm{Bi}_{2} \mathrm{Te}_{3}$ specific heat capacity; however, only one was fitted. Based on the second data set, it is reasonable to extend the low end of the temperature range from $360 \mathrm{~K}$ down to about $150 \mathrm{~K}$. This gives all properties of Table III a minimum and maximum temperature range of usage between $150 \mathrm{~K}$ and $570 \mathrm{~K}$. This is sufficient range to cover the range of temperature in the experiment.

$$
\begin{aligned}
k_{\mathrm{p}}= & k_{\mathrm{n}}=\left[\left(62605-277.7 T+0.4131 T^{2}\right) \times 10^{-4}\right] \\
& \times 1 \mathrm{~W} \mathrm{~m}^{-1} \mathrm{~K}^{-1}
\end{aligned}
$$

$$
\begin{aligned}
\alpha= & {\left[\alpha_{\mathrm{p}}-\left(-\alpha_{\mathrm{n}}\right)\right]=\left[2 \times\left(22224+930.6 T-0.9905 T^{2}\right)\right.} \\
& \left.\times 10^{-9}\right] \times 0.94 \mathrm{VK}^{-1}
\end{aligned}
$$

$$
\begin{aligned}
\rho_{\mathrm{p}}= & \rho_{\mathrm{n}}=\left[\left(5112+163.4 T+0.6279 T^{2}\right) \times 10^{-10}\right] \\
& \times 1.04 \Omega \mathrm{m}
\end{aligned}
$$

$$
\begin{aligned}
\tau= & {\left[\tau_{\mathrm{p}}-\left(-\tau_{\mathrm{n}}\right)\right]=2 \times\left(930.6 T-0.9905 T^{2} \times 2\right) } \\
& \times 10^{-9} \mathrm{VK}^{-1}
\end{aligned}
$$

$$
C_{\mathrm{p}_{\mathrm{Bi}_{2} \mathrm{Te}_{3}}}=137.49+5.7445 \times 10^{-2} T \quad \mathrm{~J} \mathrm{~kg}^{-1} \mathrm{~K}^{-1}
$$

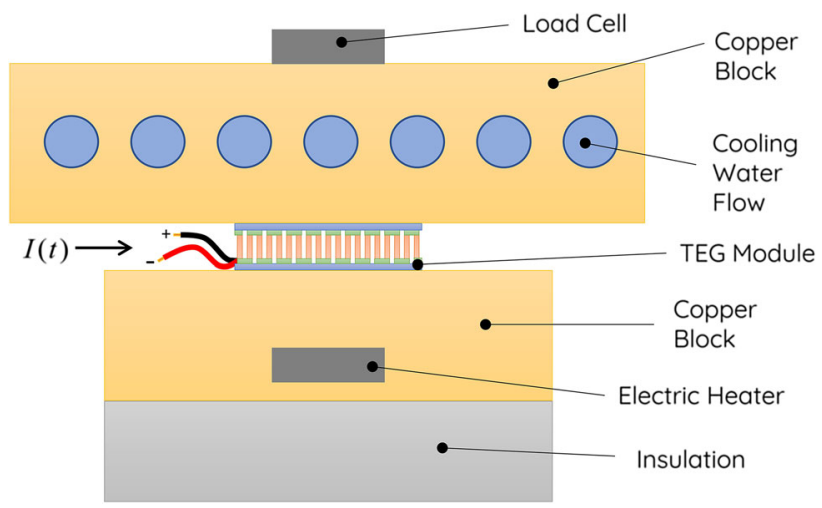

Fig. 4. Schematic of experimental data collection setup from Ref. 5.

Parameter $=\left[a T^{6}+b T^{5}+c T^{4}+d T^{3}+e T^{2}+f T+g\right] \times h$

Equation 12 is a generalized 6th order polynomial. This equation is to be used in conjunction with the coefficients $a-h$ in Table III.

\section{Experimental Data Source}

The experimental setup consisted of a thermoelectric generator module sandwiched between two copper blocks. Pressure was applied to the sandwich and monitored via a load cell (see Fig. 4). The temperature of the cold block was controlled using cooling water passages through the block. The hot block temperature was maintained by controlling the electrical current to an electric heater inside the hot block. A transient electrical current was imposed on the TEG module and can be seen in Fig. 5. Figure 6 shows the hot and cold side temperature of the thermoelectric generator ceramic outer surface over time. Many additional details can be found in Ref. 5 .

\section{CFD Data Source}

The power output of the model herein was compared in Fig. 7 against model output from a 


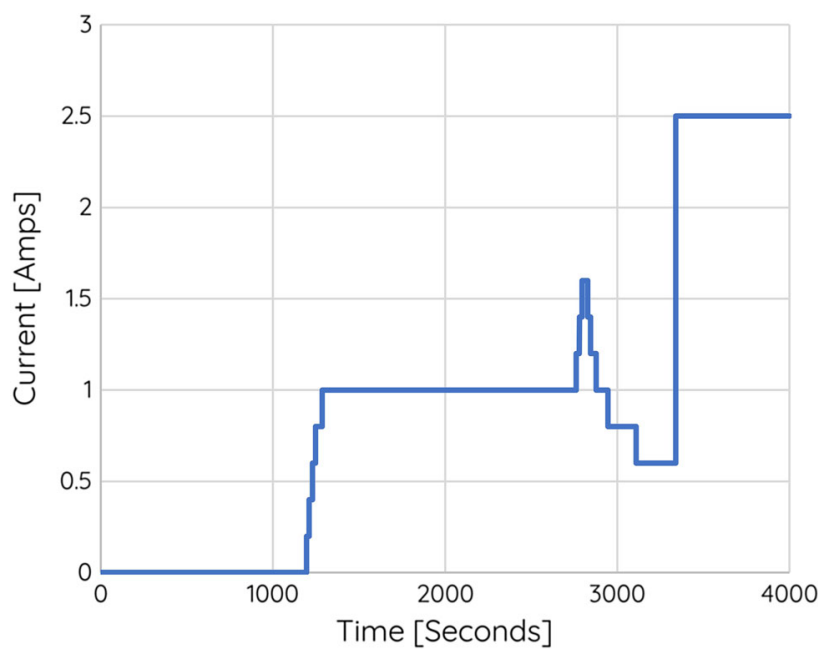

Fig. 5. Experimental electrical input current versus time from Ref. 5.

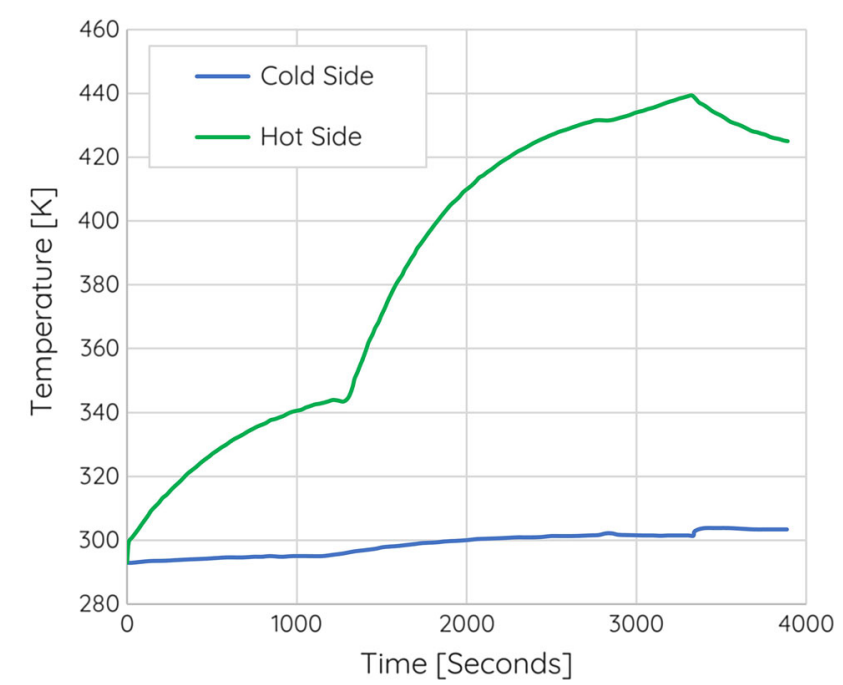

Fig. 6. Experimental hot and cold side ceramic temperature versus time from Ref. 5.

three-dimensional ANSYS $^{\mathrm{TM}}$ model. ${ }^{5}$ This ANSYS $^{\mathrm{TM}}$ CFD model used ANSYS CFX ${ }^{\mathrm{TM}}$. The CFD model used grey radiation. The cold block cooling passages (Fig. 4) were subject to a forced convection heat transfer coefficient of 1376.4 $\mathrm{W} /\left(\mathrm{m}^{2} \mathrm{~K}\right)$. The sides of the hot block were insulated and were modeled with no heat flux. The remaining surfaces were modeled with natural convection with a heat transfer coefficient of $10 \mathrm{~W} /\left(\mathrm{m}^{2} \mathrm{~K}\right)$ and $19^{\circ} \mathrm{C}$ ambient. Additional details can be found in Ref. 5 .

\section{Model Correlation with Experimental Data}

As is generally expected, the first run of the model did not provide an output that was a complete match with experimental data. This can be due to many reasons, which might include mistakes in the model inputs, imperfectly modeled physics, measurement error in the experimental data, or mismatch between measured material properties from

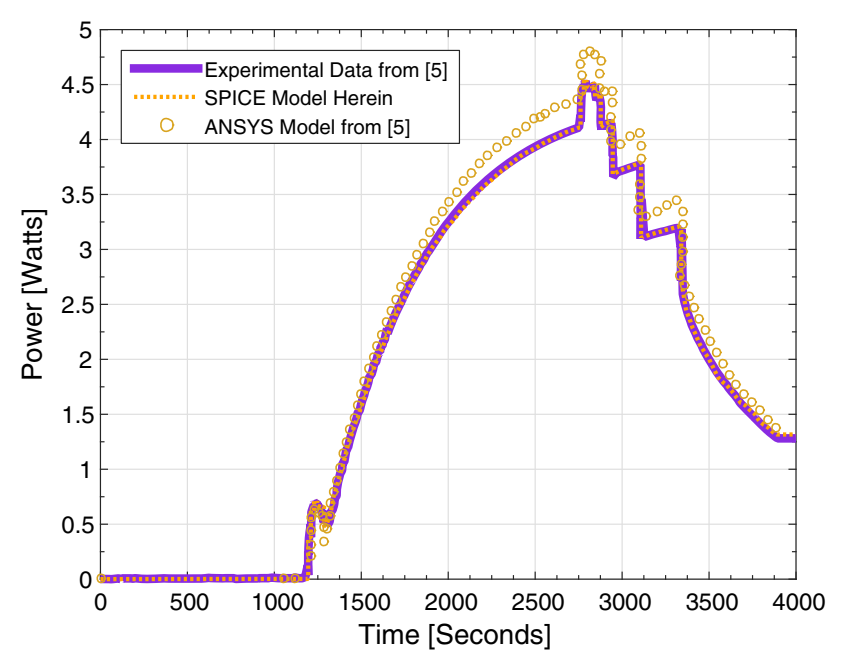

Fig. 7. Comparison of power output from correlated SPICE model herein with experimental data and 3D ANSYS ${ }^{\text {TM }}$ model from Ref. 5.

one TEG module to a separate TEG module that was used to measure module level power output.

The model herein was checked to make sure everything was performing within generally acceptable ranges and there were no mistakes in the inputs. However, verifying the other factors mentioned above in this case, was out of the scope of this work to verify. This is generally the case and means the model will need some type of correlation process to completely match up with the experimental data.

The process used for the correlation herein started with an initial sensitivity study. This was performed to determine which of many variables could be used for correlation of the model with experimental data. The power output versus time experimental data from Ref. 5 shown in Fig. 7 was the target for model correlation.

This initial sensitivity study determined qualitatively how the model output was affected by changing various model inputs. Several model inputs were ruled out for use in the correlation because there was little to no change in model output when these properties were varied over a reasonable range. The model was sensitive to dimensional changes like length, width, and height of the thermoelements. However, the chance of these dimensional inputs being a mismatch between reported values and actual value in the experiment was judged to be low, especially relative to material properties. Dimensional inputs are much more likely to match reported values because of the ease of measurement compared with material properties. Perhaps the largest factor in determining which variables to use for correlation came from the initial sensitivity study. It was determined that the module power output versus time curve could be adjusted for fit with experimental data using thermoelement properties. This did not appear to be the case with other input variables. Depending on which thermoelement property was used during 
the initial sensitivity study, different portions of the power output versus time curve would change. This was again not the case with dimensional inputs, so they offered much less correlation flexibility.

Based on these factors, thermoelement material properties seemed like the logical and probably the only choice to use for model correlation. The thermoelement properties that were adjusted and their adjustments can be seen in Eqs. 7 and 8. The constant in these equations gets multiplied by the temperature dependent material property polynomial. For the case herein, the correlated value for $\mathrm{Bi}_{2} \mathrm{Te}_{3} \rho$ was $4 \%$ higher than its original reported value and $\alpha$ was $6 \%$ lower than its original reported value.

\section{RESULTS AND DISCUSSION}

The work herein had three main objectives and three main results. The first objective that was to develop a very comprehensive, accurate and fast running model. The second objective was to correlate the developed model with experiential data. The third objective was to determine the sensitivity of the newly added sub-models. The newly added sub-models were the distributed temperature dependent thermoelectric property model, the temperature dependent nonthermoelement model, and the distributed Thomson effect model. The full model development has been discussed in "Materials and Methods" section. The results of objectives 1 and 3 are below.

\section{Model Correlation with Experimental Data}

The process of model correlation herein with experimental data has been discussed in "Model Correlation with Experimental Data" section. The results of that correlation in terms of speed and accuracy will now be discussed.

The accuracy can be seen from the results of the model correlation in Fig. 7. Here model power output is compared with experimental data and the threedimensional model output from Ref. 5. Figure 7 shows the output of the comprehensive correlated model developed herein is very well aligned with experimental data. The deviation of the SPICE model to experimental data was very small. This is important because the material property adjustments for correlation were very small to achieve the fit. The correlated value for $\mathrm{Bi}_{2} \mathrm{Te}_{3} \rho$ was $4 \%$ higher than its original reported value and $\alpha$ was $6 \%$ lower than its original reported value.

The speed of the model was also determined. The model simulated the entire $4000 \mathrm{~s}$ simulation in $2.5 \mathrm{~s}$ of real-time. The three-dimensional model ${ }^{5}$ speed was not published, but it is expected that it would take longer due to many more calculations performed within the mesh.

\section{Sensitivity Study}

The objective of the sensitivity study was to quantitatively judge the effect the added modeling features on the accuracy of the full model. The added modeling features were broken down into three sub model groups. The first was the distributed Thomson effect model, the second was the distributed temperature dependent thermoelectric property model and third was the temperature dependent non-thermoelement model.

The model herein was first correlated with experimental data. (See "Model Correlation with Experimental Data" section). This correlated model output is labeled as "Full Model" in Fig. 8.

To determine sensitivity of the distributed temperature dependent property model, the full correlated model was modified to use constant thermoelectric properties instead of the temperature dependent thermoelectric property model. The constant properties were calculated at $333 \mathrm{~K}$. The model output with these constant properties was then compared against the full model in Fig. 8. The constant property model is labeled "Full Model-Minus Temperature Dependent TE Property Model". Using constant properties caused the model to over predict and to over predict more at high temperatures and electrical currents. This may be a result of the particular mix of properties $(\alpha, \kappa, \rho)$ that are more favorable for increased power at $333 \mathrm{~K}$ than at the higher temperatures reached during the experiment. The higher deviation at higher currents is likely due to increased thermoelement internal temperature when the higher currents create more Joule heat within the thermoelements. Thus, the temperature effects are compounded.

Similarly to the way the sensitivity of temperature dependent properties were determined, the sensitivity to the temperature dependent non-thermoelement model was also determined. The temperature dependent non-thermoelement model was removed from the full comprehensive and correlated model and the power output was plotted in Fig. 8. See "Full Model-Minus Non-thermoelement Model”. Again,

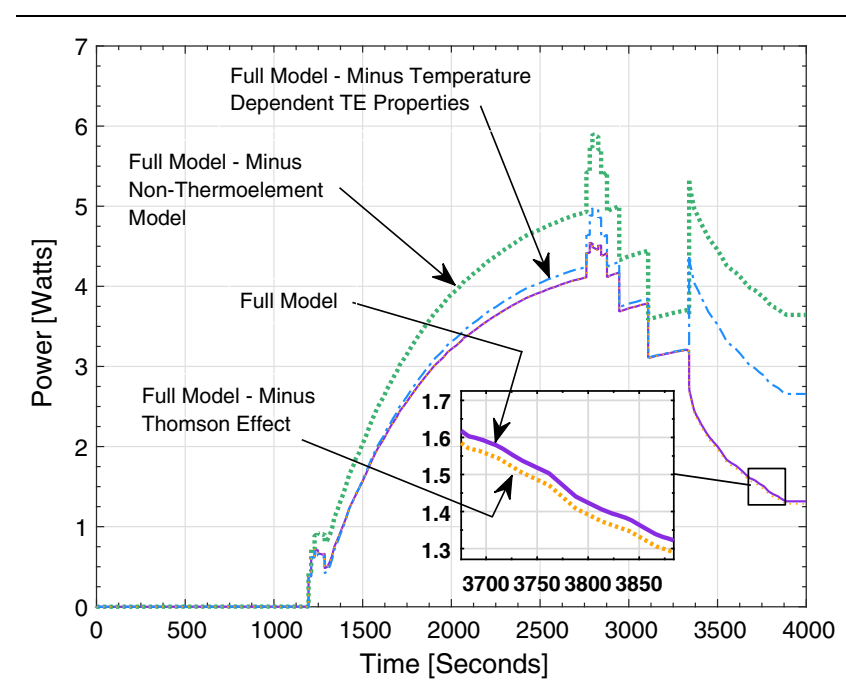

Fig. 8. Comparison of correlated SPICE model herein with itself minus certain features. 
an over-prediction of power output is seen. Without the temperature dependent non-thermoelement model, here the hot side of the thermoelement would be hotter and the cold side colder due to lower thermal resistance. This drives higher $\Delta T=T_{\mathrm{h}}-T_{\mathrm{c}}$ which is a factor in Eq. 4. The higher $\Delta T$ also drives a higher average thermoelement temperature which may or may not move the properties $(\alpha, \kappa, \rho)$ to a more favorable combination. The net effect of not having the temperature dependent non-thermoelement model, in this case, is an over prediction of power output by a significant amount.

The distributed Thomson effect was quantified in the magnified region of Fig. 8. Here it is seen that the impact of the distributed Thomson effect was very small compared to the other sub-models. This was somewhat expected since the Thomson coefficient of Eq. 10 is very small under the conditions of the experiment. At higher temperatures, the Thomson coefficient has a bigger effect on the power output of the model.

\section{CONCLUSIONS}

Thermoelectric generators have many advantages over other energy conversion technologies. They are also used in a wide array of diverse applications. Progress toward improving the current applications and toward wider acceptance of thermoelectric generators can be made by using improved modeling tools.

A literature review reveals that most available thermoelectric generator models do not include a comprehensive set of desired physics required for model accuracy.

It was the objective herein to develop that comprehensive model using a SPICE platform that is flexible and also able to run the model very quickly. A further objective was to correlate and compare the comprehensive model with experimental data. The final objective was to understand the model sensitivity to some of the newly added physics modeling features. These features were the distributed Thomson effect model, the distributed temperature dependent thermoelectric property model, and the temperature dependent non-thermoelement model.

The comprehensive model and correlation process were developed. The model correlated with experimental data very closely with a very small adjustments to the thermoelectric properties. These adjustments were a Seebeck coefficient that was $6 \%$ lower than the reported property and resistivity that was $4 \%$ higher than reported. The model also ran very fast, taking $2.5 \mathrm{~s}$ to complete the $4000 \mathrm{~s}$ transient simulation.

The impact of the newly modeling features were quantitatively determined. The temperature dependent non-thermoelement model, if not used, causes the comprehensive model to over predict TEG power output by a sizable amount. Similarly, the distributed temperature dependent model, if not used, causes a sizable over prediction in power output. The distributed Thomson effect model, if not used causes the comprehensive model to under predict power output but only by a small amount. This would vary depending on the conditions that are simulated.

\section{ACKNOWLEDGMENTS}

Thank you to Applied Thermoelectric Solutions LLC for the generous support in making this TEG model and project a reality. http://www. Thermoelec tricSolutions.com.

\section{REFERENCES}

1. A. Piggott, How Thermoelectric Generators Work. (Applied Thermoelectric Solutions LLC), https://thermoelectricsolu tions.com/how-thermoelectric-generators-work/. Accessed 1 Nov 2018.

2. D. Champier, in 3rd International Congress on Energy Efficiency and Energy Related Materials (ENEFM2015)(2017), pp. 167-181.

3. A. Piggott, Introduction to Thermoelectrics and Medical Applications. (Applied Thermoelectric Solutions LLC), https:// thermoelectricsolutions.com/introduction-thermoelectrics-me dical-applications/. Accessed 1 Jan 2018.

4. E.E. Antonova and D.C. Looman, in 24th International Conference Thermoelectrics (ICT) (2005), pp. 200-203.

5. W. Lia, M.C. Paula, A. Montecuccoa, A.R. Knoxa, J. Sivitera, N. Sellamib, X. long Mengb, E.F. Fernandezb, T.K. Mallickb, P. Mullena, A. Ashrafa, A. Samarellia, L.F. Llina, D.J. Paula, D.H. Gregoryc, M. Gaod, T. Sweetd, F. Azoughe, R. Lowndese, and R. Freere, in Energy Procedia (2015), pp. 633-638.

6. M. Jaegle, in Excerpt from the Proceedings of the COMSOL Conference 2008 Hannover (2008).

7. O. Sullivan, B. Alexandrov, S. Mukhopadhyay, and S. Kumar, J. Electron. Packag. 135, 3 (2013).

8. M. Karri, Ph.D. Thesis, Clarkson University (2011).

9. D.T. Crane, J. Electron. Mater. 40, 5 (2011).

10. A.J. Piggott and J.S. Allen, ECS J. Solid State Sci. Technol. 6, 3 (2017).

11. A.J. Piggott, Masters Thesis, Michigan Technological University (2015).

12. A.J. Piggott and J.S. Allen, ECS J. Solid State Sci. Technol. 6, 12 (2017).

13. D. Mitrani, J. Salazar, A. Turi, M.J. Garcia, and J.A. Chavez, Microelectron. J. 40, 1406 (2009).

14. M. Chen, L. Rosendahl, I. Bach, T. Condra, and J.K. Pedersen, in International Conference on Thermoelectrics (ICT) (2006), pp. 214-219.

15. A. Mirocha and P. Dziurdzia, in ICSES 2008 International Conference on Signals and Electronic Systems (2008), pp. 317-320.

16. J.A. Chavez, J.A. Ortega, J. Salazar, A. Turo and M.J. Garcia, in Conference Record: IEEE Instrumentation and Measurement Technology (2000), pp. 1019-1023.

17. S. Lineykin and S. Ben-Yaakov, in 23rd IEEE Convention of Electrical and Electronics Engineers in Israel (2004), pp. 346-349.

18. S. Lineykin, IEEE Power Electron. Lett. 3, 2 (2005).

19. L.W. Nagel and D.O. Pederson, SPICE (Simulation Program with Integrated Circuit Emphasis), Technical Report, University of California, Berkeley, (1973).

20. A.F. Robertson and D. Gross, J. Res. Natl. Bur. Stand. 61, 2 (1958).

21. T. Wey, in IEEE North-East Workshop on Circuits and Systems (2006), pp. 277-280.

22. S. Kima, S. Cho, N. Kim, and J. Park, IEICE Electron. Expr. 7, 20 (2010). 
23. V. Milanovic, M. Hopcroft, C. Zincke, M. Zaghloul, and K.S.J. Pister, Therminic 2000, International Workshop on Thermal Investigations of ICs and Systems (2000), pp. 1-5.

24. N.Q. Nguyen and K.V. Pochiraju, Appl. Therm. Eng. 51, 1 (2013).

25. R. Lamba and S.C. Kaushik, Energy Convers. Manag. 144, 388 (2017).

26. W. Thomson, Proc. R. Soc. Lond. 7, 49 (1854).

27. H. Lee, Energy 66, 56 (2013).

28. D.M. Avadhanulu and D.P. Kshirsagar, A Textbook of Engineering Physics (Ram Nagar, S. Chand \& Company PVT. LTD, 2008), pp. 435-446.

29. S. Riffat, X. Ma, and R. Wilson, Appl. Therm. Eng. 26, 5 (2006).

30. GM250-127-14-10 Thermoelectric generator module data sheet, European Thermodynamics Limited (2017).

31. The National Institutes of Health (NIH), Pubchem Compound Database (Compound Summary for CID 6379155 Bismuth Telluride), https://pubchem.ncbi.nlm.nih.gov/com pound/6379155 Accessed Jan 2018.

32. A.S. Pashinkin, A.S. Malkova, and M.S. Mikhailova, Izv. Vyssh. Uchebn. Zaved., Elektron. 5, 78 (2007).
33. Y.I. Shterna, S. Malkovaa, and S. Pashinkin, Inorg. Mater. (2008). https://doi.org/10.1134/S0020168508100051.

34. Purdue University, Volume 4, (The Macmillan Company, Collier-Macmillan Limited, New York, 1967), pp. 30-40.

35. T.L. Bergman, A.S. Lavine, F.P. Incropera, and D.P. Dewitt, Fundamentals of Heat and Mass Transfer, 7th Edn (Wiley, New York, 2011), p. 983.

36. Melcor, Thermoelectric Handbook, Unknown.

37. Alasir, Solder alloys: physical and mechanical properties, http://alasir.com/reference/solder_alloys/162. Accessed 2 Jan 2018.

38. Matweb Material Property Data, Indium corp. indalloy 106 (sn63) sn-pb solder alloy, http://www.matweb.com/search/da tasheet.aspx? matguid=c1d1b91a360748bf9944a0c771e8d5b $2 \& c k c k=1$. Accessed 18 Feb 2018.

39. J.G. Bai, Z.Z. Zhang, G.Q. Lu, and D.P.H. Hasselman, Int. J. Thermophys. 26, 5 (2005).

40. C.N. Liao, C.H. Lee, and W.J. Chen, Electrochem. Solid State Lett. 10, 9 (2007).

41. L.W. da Silva and M. Kaviany, Int. J. Heat Mass Transf. 47, 2417 (2004).

42. R.A. Matula, J. Phys. Chem. Ref. Data 8, 1147 (1979). 